\title{
Estimation of Environmental Damages of Cement Building and Environmental Benefits of Prefabricated Building: A Case Study Based on a Residential Project in Henan Province, China
}

\author{
Chen Nan $\dagger$ and Zhang Jie \\ Department of Architectural Engineering, Jiyuan Vocational and Technical College, Jiyuan 459000, China \\ †Corresponding author: Chen Nan; jynancy86@126.com
}

Nat. Env. \& Poll. Tech. Website: www.neptjournal.com

Received: 22-02-2020

Accepted: 24-04-2020

Key Words:

Cement building;

Environmental damage;

Prefabricated building;

Environmental benefit;

\begin{abstract}
Traditional cement building generates abundant construction wastes during construction and waste transportation. Thus, it incurs high building resource consumption, low building efficiency, and frequent occurrence of safety accidents, which result in relatively low utilization ratio of building resources and relatively serious environmental pollution pressure. A prefabricated building can save building materials and energies and decrease construction waste emission; it is also an essential choice when the construction industry develops to a high level in a country. A case study based on a residential project in Henan Province, China was carried out. Firstly, studies concerning the environmental benefits of prefabricated building in foreign developed countries were reviewed. Second, the types of environmental damage from cement building were summarized. Third, an evaluation index system of environmental benefits of the prefabricated building was established. Finally, environmental benefit scores in the case study were calculated using the fuzzy comprehensive evaluation method based on the analytic hierarchy process. Results demonstrated that prefabricated building is extensively applied in Europe. Traditional cement buildings bring various types of environmental pollution, including water, solid waste, and dust pollutions and vegetation damage. In a case study, the environmental benefits of the prefabricated building are assessed at a good level close to excellent. Environmental benefits of the prefabricated building can be improved by encouraging real estate developers to adopt prefabricated building. In this manner, the installation efficiency of mechanical devices and construction efficiency can be increased, and the construction safety of projects can be improved. Research conclusions can provide references not only for the government to formulate policies in favour of prefabricated building development and measures for reducing environmental pollutions but also for the construction industry to enrich benefit evaluation systems for prefabricated building projects. This study is highly important in the realization of green sustainable development in the construction industry.
\end{abstract}

\section{INTRODUCTION}

Recently, the construction industry has achieved considerable progress as a response to the rapid development of China's real estate industry. China has begun to explore building industrialization since the 1950s, which brought China's building industrialization into a new fast development stage. Disadvantages of traditional cast-in-place construction mode, such as high energy consumption, heavy pollution, low efficiency, and low quality, become increasingly prominent. Particularly, cement dust during construction activities is produced by human activities. The dust particles move with airflow under the influence of human activities and finally become tiny particles that are easy to be inhaled by humans. These tiny particles cause a series of diseases (e.g., pneumoconiosis) and even threaten human life once they infect the lungs. Moreover, a considerable amount of dust in the atmosphere will be produced by human activities or machine operation during construction; this phenomenon increases dust concentration and lowers air quality. Particularly, dust concentration has severely exceeded the limit in the metropolis. Dust can affect the growth of surrounding plants and the physical health of human beings because it contains a large amount of heavy metals and other compounds, which easily generate toxic substances after a reaction. Developing prefabricated building is conducive for the promotion of the formation of an emerging industry and deep integration of the construction industry with industrial construction, information, logistics, and modern service industries. This approach has a positive effect on developing a new economy and new energy and promoting economic growth by driving social investment.

Henan is a province in Central China with a large population. As shown in Fig. 1, the permanent resident population increased from 94.87 million in 2009 to 96.05 million in 2018. Moreover, the urbanization process in Henan Province accelerated due to population aggregation. The total output 
of the construction industry increased from 359.649 billion yuan in 2009 to 1136.052 billion yuan in 2018, showing an annual growth rate of as high as $24 \%$. This result fully reflects the large pressure of the construction industry over the environmental pollution in Henan Province. However, the disadvantages of traditional construction mode in Henan Province became increasingly prominent due to the excessive energy and resource consumption by the construction industry, serious ecological environmental damage, backward production management mode, and low technological level of firstline operators. Therefore, the development of prefabricated building in China is facilitated considerably by assuring transformation and updating of the construction industry, thereby developing the guidance role of the government, offering enterprises certain preferential subsidy policies, and motivating enterprises to change their traditional construction modes. Demonstration bases of the prefabricated building have been constructed in the major cities of Henan Province to promote the local development of the prefabricated building. Promoting construction industrialization can lower the consumption of building resources and energy effectively, increase economic benefits, decrease wet operation and construction noises in the construction site, and improve heat-insulating performance compared with cast-in-site construction. In sum, the prefabricated building can save energy sources and decrease environmental pollution significantly.

\section{PAST STUDIES}

Environmental pollution caused by traditional cement building has attracted global concerns. A prefabricated building that can decrease environmental pollution effectively is a mainstream development trend of the global construction industry. After World War II, many houses were ruined. In this background, prefabricated buildings were developed and became an important development opportunity for its unique production characteristics, such as the short construction period and high construction speed. Prefabricated buildings have caused a series of housing industrialization tides. At present, the increasingly mature prefabricated building technology in Europe is attributed to the continuous studies of many scholars. With respect to environmental pollution caused by traditional cement building, Morledge et al. reported that the construction industry has the highest pollution frequency among industries, accounting for $22 \%$ of confirmed water pollution events of the industry. Finally, the author proposed some measures on how to relieve the adverse impact of the construction industry on the environment (Morledge et al. 2001). Yang et al. analysed China's control standards for solid waste pollution caused by cement products and pointed out that solid waste pollution caused by cement building was one source of solid waste pollution (Yang et al. 2011). Wu et al. indicated that the large-scale

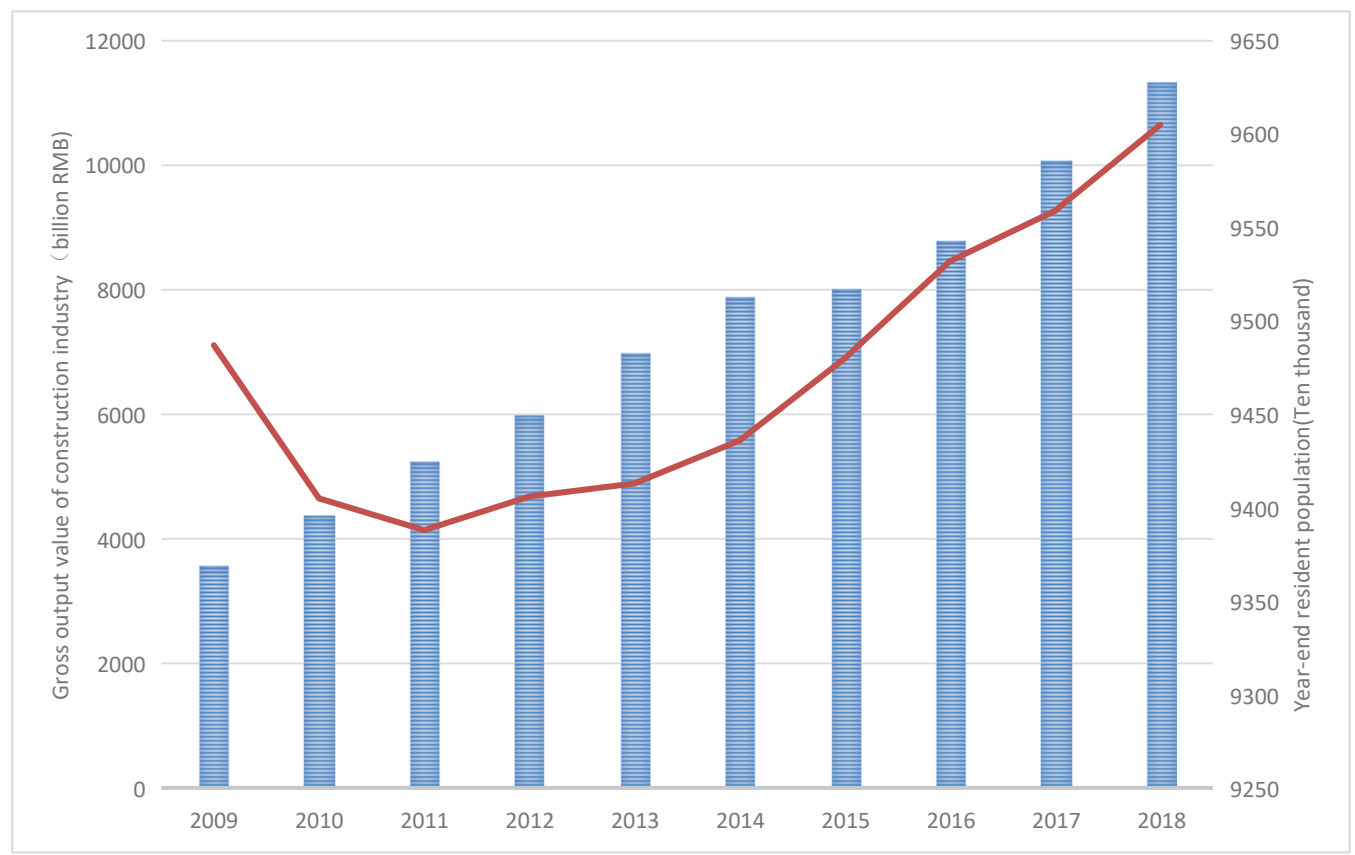

Fig. 1: Permanent resident population and total output of the construction industry at end of a year in Henan Province during 2009-2018. (Data source: China Statistics Database: http://data.stats.gov.cn). 
construction of cement buildings is a result of the accelerating urbanization process in China, which has brought considerable dust emissions. Based on the investigations on the current dust control status of China's construction industry, the authors determined the main source of construction dust and finally proposed measures to control construction dust pollution (Wu et al. 2016). Wang et al. investigated the differences in the environmental effects of prefabricated plates, composite plates, and cement pouring construction during their life cycles and analyzed the influence of building life on construction environmental pollutant emissions. The authors found that abundant buildings are dismantled during China's urbanization process, which shortens the average life of buildings and wastes a considerable amount of energies and resources (Wang et al. 2018). Tam et al. analyzed and studied the reduction of construction wastes of four prefabricated buildings compared with those of traditional cast-insite buildings and proposed the environmental benefits of prefabricated buildings in terms of energy-saving and emission reduction. The authors concluded that the construction waste production and the template quantity of prefabricated buildings are approximately 55\% and $80 \%$ lower than those of traditional cast-in-site construction, respectively (Tam et al. 2005). Jaillon et al. believed that the standard design of prefabricated buildings not only can increase production efficiency of product parts effectively but also has advantages of energy-saving, emission reduction, and relieving environmental pollutions. Therefore, they suggested the promotion and application of prefabricated buildings on a large scale (Jaillon et al. 2009). Pons et al. studied the influence of school construction on the environment based on the industrialization technology in Catalonia, Spain. They found that using prefabricated buildings could decrease resource consumption, waste production, and environmental pollutions (Pons et al. 2011). Silva et al. constructed a three-dimensional model for the module reconstruction of the external walls of existing prefabricated buildings and analyzed its cost efficiency (Silva et al. 2013). Lehmann reported that the promotion of low-carbonization construction of prefabricated buildings can decrease greenhouse gas emissions of building materials. The author suggested that the government should reduce taxis for the use of renewable energy houses and offer fiscal subsidies to real estate developers who meet certain conditions (Lehmann 2013). Mao et al. discussed the differences between prefabricated and traditional construction modes in greenhouse gas emission and confirmed that the former has significant environmental benefits on greenhouse gas emission (Mao et al. 2013). In the theoretical background of the full life cycle, Lu discussed the potential of prefabricated building technology in waste reduction in the construction and transnational transportation industries. The results showed that prefabrication in a factory environment can decrease wastes more than traditional castin-site construction does ( $\mathrm{Lu} 2013$ ). Bonamente et al. investigated the prefabricated building department in Italy. They analyzed the carbon and energy footprints of prefabricated components in preproduction, in-production, assembly, use, and dismantling stages. They also discussed the influence types of prefabricated buildings on the environment and finally proposed corresponding suggestions to decrease environmental impact (Bonamente et al. 2014). Dong et al. performed a case study based on a private house in Hong Kong to compare the carbon emissions of prefabricated technology and traditional cast-in-site construction technology. Based on their results, they strongly suggested the adoption of prefabricated concrete during construction, which can decrease the carbon emission of the construction industry (Dong et al. 2015). Jeong et al. evaluated the differences between new prefabricated columns and traditional concrete columns in terms of productivity, cost, and $\mathrm{CO}_{2}$ emission through a case study. They concluded that the former increased productivity by $42.5 \%$ and saved costs by $1.32 \%$. Moreover, the new fabricated column is a reliable substitute for traditional concrete columns (Jeong et al. 2017). On the basis of the aforementioned studies, traditional cement buildings may cause considerable environmental pollution in construction and building recycling, whereas prefabricated buildings can decrease the consumption of construction resources and energies and increase economic benefits. However, existing studies on prefabricated building mainly focus on design, construction technology, cost control, and economic benefits. Only few studies on environmental benefits of the prefabricated building have been reported. Thus, in the present work, a case study based on a residential project community in Henan Province was performed. Weights of major evaluation indexes were determined by analytic hierarchy process (AHP), and environmental benefits of the prefabricated building project were calculated using a fuzzy comprehensive evaluation method. Some specific improvement suggestions were proposed based on the evaluation results.

\section{ENVIRONMENTAL DAMAGE CAUSED BY CEMENT BUILDING}

\section{Water Pollution}

Traditional cement building in cities inevitably produces sewage and industrial slurry during construction. Many construction units lack essential environmental protection consciousness and pursue economic benefits blindly by discharging slurry and sewage directly rather than after purification. As a result, sewage in the construction site containing industrial raw materials, cement mortar, sundries, and dust 
is discharged to surrounding sewers of the construction site directly, causing serious pollution to surrounding water areas. In the long run, the sub drainage systems in cities will be blocked by these sundries and slurries, which will decrease drainage and flooding prevention capacities significantly. Some construction projects will even affect the underground water level in cities during the construction of the foundation.

\section{Solid Waste Pollution}

Generally, cement building projects will surely produce a considerable amount of solid wastes, such as graves and slags during construction, which often brings a great challenge in disposal. Such solid wastes generally have no value of recycling and incur high processing costs. Many construction projects directly pour these solid wastes in open areas in suburbs or landfilled directly to save processing cost, which will cause relatively serious soil pollution in local areas and occupy spaces for processing other household wastes.

\section{Dust Pollution}

Dust pollution, which is produced in the construction sites of cement buildings, mainly comes from the transportation of materials. Handling of raw materials and earthwork in the site can cause dust pollution. Dust pollution can also be generated when construction workers are paving pipeline network and transporting materials, such as cement and lime. If dust concentration becomes thick during construction, then a considerable amount of dust will be lifted into the air when vehicles drive quickly. Waste gases, which are produced during construction, generally come from construction materials, such as paints or other decoration materials. These materials will generate some harmful gases in special environments and places with a large population. The physical health of individuals is exposed to serious damage.

\section{Vegetation Damage}

Road network in Chinese cities is expanding, accompanied by endless emergence of high-rise residential building projects and business district construction projects. All of these require plentiful cement pouring tasks. During land development, cement building projects ignore water and soil protection in the construction field. Many construction sites do not comply with the regulation of setting retaining walls and revetment. Many land development regions become idle after smoothing and exposure to air and may thus suffer serious water and soil losses after being scoured by rainstorms. In the long run, it will cause serious mud accumulation in the river, reservoir sedimentation, and gradual failure of the drainage system in urban areas.

\section{BRIEF INTRODUCTION OF THE MODEL AND INDEX SYSTEM}

\section{Brief Introduction of the Model (AHP-based Fuzzy Comprehensive Evaluation)}

(1) Determination of weights of indexes (AHP method): The AHP is a multicriteria decision method that combines qualitative and quantitative analyses. It divides evaluation indexes into several layers and quantizes qualitative understanding of people through certain scales. On this basis, qualitative and quantitative analyses are performed. Weights of evaluation indexes can be gained through AHP, as shown as follows:

$$
W=\left[w_{1}, w_{2}, \cdots, w_{n}\right],
$$

Where, $w_{n}$ refers to the weights of the nth index calculated by the AHP.

(2) Construction of comment set: The set of experts' comments for the comprehensive evaluation of prefabricated building project is set up and defined as

$$
V=\left\{v_{1}, v_{2}, \cdots, v_{n}\right\} \text {, }
$$

where $v_{n}$ is the evaluation grade of the project, which generally includes excellent, good, moderate, poor, and very poor. For the convenience of calculation, the common method in most associated studies is used in defining the five grade levels of excellent, good, moderate, poor, and very poor, which are equivalent to $95,85,75,65$, and 55 , respectively. Next, the evaluation factor set is determined again, as shown as follows:

$$
U=\left\{u_{1}, u_{2}, \cdots, u_{n}\right\},
$$

where $u_{i}$ is the $i^{\text {th }}$ influencing factor of the evaluated object.

(3) Construction of a membership matrix for project evaluation: Subsequently, technicians of the studying prefabricated building project were invited to score the index system, obtaining a membership matrix $(B)$.

(4) Final scores: Finally, the final scores are calculated through weighted averaging of scores in accordance with the comment set. The final scores are defined as $C$, as shown as follows:

$$
C=W^{*} B *[95,85,75,65,55]^{T} .
$$

\section{Index System}

Fabricated buildings decrease environmental resource wastes and energy consumption effectively because of their capacity to overcome the disadvantages of traditional construction mode to some extent. This study selected five representative indexes on the basis of the influence of fabricated building construction on the environment (Table 1). 


\section{CASE STUDY}

The study area lies in Zhenzhou City, Henan Province. It covers a construction land area of $45,230 \mathrm{~m}^{2}$, and the planning built-up area is approximately $130,000 \mathrm{~m}^{2}$, which includes 12 floors. The area can meet the needs of 2,310 replacement households. This project adopted prefabricated building technology and, all prefabricated parts were all manufactured and supplied by a construction company in Zhenzhou City, Henan Province.

\section{Determination of Weight Indexes}

According to the AHP model for environmental benefit evaluation of the study project, a questionnaire survey was filled out by 10 members of the project team using 1-9 scale criteria.

On the basis of the judgment matrix in Table 2, the eigenvector and maximum eigenvalue of the judgment matrix are calculated by the most common square root method in the AHP model. They were applied to check whether judgment matrixes meet the consistency requirement (Table 3).

Table 3 shows that all judgment matrixes meet the consistency test.

\section{Membership Matrix}

Ten members of the project team were invited again to score the environmental benefit indexes of the project. Table 4 lists the results.

On the basis of the scores in Table 4, the membership matrix is gained as follows:

$$
B=\left[\begin{array}{lllll}
0.3 & 0.6 & 0.1 & 0 & 0 \\
0.6 & 0.3 & 0.1 & 0 & 0 \\
0.8 & 0.1 & 0.1 & 0 & 0 \\
0.5 & 0.3 & 0.2 & 0 & 0 \\
0.1 & 0.2 & 0.5 & 0.2 & 0
\end{array}\right]
$$

\section{Final Scores}

On the basis of Eq. (3), the final scores are calculated as follows:

$$
C=[0.246,0.158,0.39,0.130,0.076]^{*}\left[\begin{array}{ccccc}
0.3 & 0.6 & 0.1 & 0 & 0 \\
0.6 & 0.3 & 0.1 & 0 & 0 \\
0.8 & 0.1 & 0.1 & 0 & 0 \\
0.5 & 0.3 & 0.2 & 0 & 0 \\
0.1 & 0.2 & 0.5 & 0.2 & 0
\end{array}\right] *[95,85,75,65,55]^{\mathrm{T}}
$$

The final scores of the environmental benefit are $\mathrm{C}=88.794$. Table 5 shows the relations between environmental benefit scores and evaluation levels are shown in Table 5 .

$\mathrm{C}=88.794$ indicates that the environmental benefit of prefabricated building is at a good level and it is close to the excellent level. Thus, the prefabricated building project in this case study achieved "good" environmental benefits, which indicates that it presented good environmental benefits. Therefore, the prefabricated building technology was proven to save resources and energies significantly, as well as decrease production of construction wastes and dust emission. Furthermore, with the reduction of wet operation quantities, noises from the use of mechanical devices were decreased, and the living environmental quality for surrounding residents was improved significantly. The studied prefabricated building realized the goal of "water-saving, land saving, energy saving, material saving and environmental protection" through standard design and unique characteristics. The unique energy-saving design was made according to the functions of the building. In the design stage, the prefabricated building's demands for construction site were decreased significantly because most parts were prefabricated in factories. In the construction stage, the installation of prefabricated parts could increase the utilization of water resources significantly compared with that in traditional cast-in-site mode. In the use stage, the prefabricated building could increase the utilization of parts and saving materials through unique standard design and energy design. In the

Table 1: Evaluation index system of the environmental benefits of prefabricated buildings.

\begin{tabular}{|ll|}
\hline Indexes & Explanation \\
\hline Resource consumption $\left(\boldsymbol{w}_{\mathbf{1}}\right)$ & $\begin{array}{l}\text { House construction has great resource consumption. Resource consumption is an indispensable index in the eval- } \\
\text { uation of environmental benefits. }\end{array}$ \\
Energy consumption $\left(\boldsymbol{w}_{\mathbf{2}}\right)$ & $\begin{array}{l}\text { House energy consumption mainly refers to daily energy consumption needed for heating, air conditioning, and } \\
\text { illumination of the house. } \\
\text { Solid waste emission }\left(\boldsymbol{w}_{\mathbf{3}}\right)\end{array}$ \\
$\begin{array}{l}\text { Solid wastes mainly refer to those that are produced during construction and dismantling stages of houses. } \\
\text { Noise pollution }\left(\boldsymbol{w}_{\mathbf{5}}\right)\end{array}$ & $\begin{array}{l}\text { Dust emission refers to the sum of various dust types produced during house construction. } \\
\text { During house construction, noises mainly come from frequent uses of large-size mechanical devices. }\end{array}$ \\
\hline
\end{tabular}


Table 2: Judgment matrix of environmental benefits.

\begin{tabular}{|c|c|c|c|c|c|}
\hline & $\mathrm{w}_{1}$ & $\mathrm{w}_{2}$ & $\mathrm{w}_{3}$ & $\mathrm{w}_{4}$ & $\mathrm{w}_{5}$ \\
\hline$w_{1}$ & 1 & 3 & 1 & 1 & 2 \\
\hline$w_{2}$ & $1 / 3$ & 1 & $1 / 3$ & 2 & 3 \\
\hline$w_{3}$ & 1 & 3 & 1 & 4 & 5 \\
\hline$w_{4}$ & 1 & $1 / 2$ & $1 / 4$ & 1 & 2 \\
\hline$w_{5}$ & $1 / 2$ & $1 / 3$ & $1 / 5$ & $1 / 2$ & 1 \\
\hline
\end{tabular}

dismantling stage, the prefabricated building had prominent environmental protection performance compared with the traditional cast-in-site mode. For example, the safety of building dismantling was increased, and a high recycling rate of parts was achieved.

\section{POLICY SUGGESTIONS}

\section{Encouraging Real Estate Developers to Adopt \\ Prefabricated Buildings to Decrease Overall Environmental Pollution}

The government sectors shall offer preferential taxes to real estate developers who adopt prefabricated building mode to relieve their financial pressure from economic cost. Direct economic expenditures of real estate developers for prefabricated building can be compensated by using various forms of tax preference policies, such that real estate developers are more willing to adopt prefabricated building mode. The increasing prefabricated building projects in the market is the fundamental source of promoting the expansion of market demands. Only expanding the scales of prefabricated component demands can further promote the development of part manufacturers, installation professionals, and construction enterprises. In the early industrial development stage, subsidies can be provided to real estate developers through various ways, such as exemption from tax, tax reduction, or tax reimbursement, which can effectively promote the development of prefabricated buildings.

\section{Increasing Installation Efficiency of Mechanical Devices and Decreasing Noise Pollution and Dust Emission}

At present, few installation devices support prefabricated buildings, and most prefabricated parts are installed using basic hoisting devices. This situation not only leads to low installation efficiency but also significantly intensifies noise pollution during installation compared with that in foreign countries. Hence, providing professional installation services can solve the low assembly efficiency of mechanical devices directly, thereby decreasing unnecessary noise pollution problems caused by the low efficiency of devices. Prefabricated part manufacturers are encouraged to expand their business scope and provide house assembly services while meeting prefabricated part manufacturing demands of real estate developers. Through the training of installation skills of operators, a group of technicians who are skilled in the installation of mechanical devices can be trained. As a result, resource waste caused by damage of prefabricated parts during the use stage of installation devices can be decreased. Moreover, these technicians can increase installation efficiency and decrease noise pollutions during installation.

\section{Increasing Construction Productivity and Reducing Environmental Influencing Period of Projects}

Prefabricated buildings can also affect the daily life of surrounding residents during construction to some extent. During construction, noises, dust, solid waste, and road blocking all bring great inconveniences to normal life and rests of residents. Such influence is related to time. Therefore, construction productivity can increase social benefits significantly. Increasing construction productivity can shorten the construction period, relieve the effects of construction activities on surrounding residents, increase the quality performance of house products, and meet the diversified demands of residents. In prefabricated buildings, residents can make appropriate reconstruction of houses according to personnel demands. Moreover, early planning design provides diversified house types that can meet the living demands of different groups. Prefabricated buildings claim relatively low costs for repairing or maintenance and long maintenance period because of the abundant use of prefabricated parts. In addition, a maintenance property team is set

Table 3: Eigenvector and maximum eigenvalue of judgment matrixes.

\begin{tabular}{|lll|}
\hline Eigenvector $W$ & $\lambda_{\max }$ & $C I$ \\
\hline$(0.246,0.158,0.390,0.130,0.076)$ & 5.371 & 0.082 \\
\hline
\end{tabular}


Table 4: Statistics on scores of environmental benefit evaluation indexes.

\begin{tabular}{|c|c|c|c|c|c|}
\hline \multirow{2}{*}{ Indexes } & \multicolumn{5}{|c|}{ Evaluation results } \\
\hline & Excellent & Good & Moderate & Poor & Very poor \\
\hline Resource consumption $\left(\boldsymbol{w}_{\mathbf{1}}\right)$ & 3 & 6 & 1 & 0 & 0 \\
\hline Energy consumption $\left(\boldsymbol{w}_{\mathbf{2}}\right)$ & 6 & 3 & 1 & 0 & 0 \\
\hline Solid waste emission $\left(\boldsymbol{w}_{\mathbf{3}}\right)$ & 8 & 1 & 1 & 0 & 0 \\
\hline Dust emission $\left(\boldsymbol{w}_{\mathbf{4}}\right)$ & 5 & 3 & 2 & 0 & 0 \\
\hline Noise pollution $\left(\boldsymbol{w}_{\mathbf{5}}\right)$ & 1 & 2 & 5 & 2 & 0 \\
\hline
\end{tabular}

up for the community to make common plans for existing problems, choose the most reasonable maintenance schemes, and settle disputes over house maintenance.

\section{Increasing Construction Safety of Project and Decreasing the Adverse Effects of Construction Activities on the Environment}

In comparison with traditional construction, prefabricated building projects involve few construction workers, which can decrease the number of injury accidents and adverse social impacts dramatically. The adverse impacts of high injuries and deaths in the traditional construction mode on the society can be changed by improving construction safety. Prefabricated buildings produce a good demonstration effect in the inner heart of surrounding residents and increase social benefits. On this basis, this study suggests to (1) increase construction safety, set up strict construction safety norms, and regularly examine the implementation progress to realize civilized construction and safety construction; (2) construct a weekly safety summary system to point out attentions and remind construction workers to be always alert to prevent accidents strictly; and (3) increase training to construction workers to improve their technological skills and decrease safety accidents caused by inadequate technological abilities.

\section{CONCLUSIONS}

China's urbanization achieves outstanding progress because of its rapid economic development, which drives the continuous expansion of the construction industry in China. The traditional cast-in-site mode still takes the dominant role in China's construction industry. This traditional mode is characterized by great resource consumption, low construction efficiency, frequent occurrence of safety events, and serious environmental pollution. Prefabricated buildings balance the contradiction between economic development and environmental protection and meets the demands for green development. Thus, such buildings are an essential choice for green sustainable development of the construction industry. This work performs a case study based on a residential project in Henan Province. Here, the types of environmental damage caused by cement building are summarized, and environmental benefit scores are calculated by an AHP-based fuzzy comprehensive evaluation method. The results indicate that water pollution, solid waste pollution, dust pollution, and vegetation damage are four major pollution types caused by traditional cement building. In this case study, the environmental benefits of the prefabricated building are at a good level and close to the excellent level. Finally, some suggestions are proposed, including encouraging real estate developers to adopt prefabricated buildings, increasing installation efficiency of mechanical devices, increasing construction productivity, and improving the construction safety of projects. Further studies on increasing environmental benefit evaluation accuracy based on further refined classification, calculating environmental benefits of the prefabricated building by combining multiple evaluation methods, and enriching the comprehensive evaluation systems of full-process environmental benefits of the prefabricated building should be conducted.

\section{REFERENCES}

Bonamente, E., Merico, M. C., Rinaldi, S., Pignatta, G., Pisello, A., Cotana, F. and Nicolini A. 2014. Environmental impact of industrial prefabricated buildings: carbon and energy footprint analysis based on an LCA approach. Energy Procedia, 61: 2841-2844.

Dong, Y. H., Jaillon, L., Chu, P. and Poon, C. 2015. Comparing carbon emissions of precast and cast-in-situ construction methods-A case study of high-rise private building. Construction and Building Materials, 99: 39-53.

Table 5: Evaluation results and definition of the five grade levels.

\begin{tabular}{|llllll|}
\hline Levels & Excellent & Good & Moderate & Poor & Very poor \\
\hline Scores & {$[90)$,} & {$[80,90)$} & {$[70,80)$} & {$[60,70)$} & {$[0,60)$} \\
\hline
\end{tabular}


Jeong, J., Hong, T., Ji, C., Kim, J., Lee, M., Jeong, K. and Lee, S. 2017. An integrated evaluation of productivity, cost and $\mathrm{CO} 2$ emission between prefabricated and conventional columns. Journal of Cleaner Production, 142: 2393-2406.

Jaillon, L. and Poon, C. S. 2009. The evolution of prefabricated residential building systems in Hong Kong: A review of the public and the private sector. Automation in Construction, 18(3): 239-248.

Lehmann, S. 2013. Low carbon construction systems using prefabricated engineered solid wood panels for urban infill to significantly reduce greenhouse gas emissions. Sustainable Cities and Society, 6: 57-67.

Lu, W. and Yuan, H. 2013. Investigating waste reduction potential in the upstream processes of offshore prefabrication construction. Renewable and Sustainable Energy Reviews, 28: 804-811.

Mao, C., Shen, Q., Shen, L. and Tang, L. 2013. Comparative study of greenhouse gas emissions between off-site prefabrication and conventional construction methods: Two case studies of residential projects. Energy and Buildings, 66: 165-176.

Morledge, R. and Jackson, F. 2001. Reducing environmental pollution caused by construction plant. Environmental Management and Health,
12(2):191-206.

Tam, C. M., Tam, V. W. Y., Chan, J. K. W. and Ng, W. C. Y. 2005. Use of prefabrication to minimize construction waste-a case study approach. International Journal of Construction Management, 5(1): 91-101.

Pons, O. and Wadel, G. 2011. Environmental impacts of prefabricated school buildings in Catalonia. Habitat International, 35(4): 553-563.

Silva, P. C. P., Almeida, M., Bragança, L. and Mesquita, V. 2013. Development of prefabricated retrofit module towards nearly zero energy buildings. Energy and Buildings, 56: 115-125.

Wang, J., Zhang, Y. and Wang, Y. 2018. Environmental impacts of short building lifespans in China considering time value. Journal of Cleaner Production, 203: 696-707.

Wu, Z., Zhang, X. and Wu, M. 2016. Mitigating construction dust pollution: State of the art and the way forward. Journal of Cleaner Production, 112: 1658-1666.

Yang, Y., Huang, Q., Yang, Y., Huang, Z. and Wang, Q. 2011. Formulation of criteria for pollution control on cement products produced from solid wastes in China. Journal of Environmental Management, 92(8): 1931-1937. 